\section{Correspondence on 'EULAR/ACR classification criteria for adult and juvenile idiopathic inflammatory myopathies and their major subgroups'}

The publication of the European League Against Rheumatism/American College of Rheumatology (EULAR/ACR) 2017 classification criteria for adult and juvenile idiopathic inflammatory myopathy is a landmark with 186 citations as of date. ${ }^{1}$ Patients with dermatomyositis (DM) and polymyositis (PM) differ with respect to clinical features, autoantibody profile and treatment response and have been subgrouped for a long time now. ${ }^{2}$

We studied 26 consecutive adult patients over 1 year seen in a tertiary teaching hospital in south India, satisfying either the 2017 criteria or 1975 Bohan-Peter criteria for idiopathic inflammatory myositis (IIM). Patients were subclassified using the 2017 criteria subclassification tree. Those with typical skin rash (heliotrope, Gottron papule or Gottrons sign) were classified as DM $(n=14)$ and the rest as PM $(n=12)$. There were no patients satisfying the criteria for IBM. Overlap myositis was excluded.

As is evident from table 1; seven patients in the PM group had non-classic skin rash (generalised erythematous rash or malar rash). These patients had received a bedside diagnosis of DM. Five of these patients had DM-associated myositis-specific antibodies (MSA) in serum (four anti-Mi2, one anti-NXP2) and perifasicular atrophy on muscle biopsy, another characteristic features of classical DM (specificity $>90 \%$, sensitivity $30 \%-50 \%$ ).

Using the International Myositis Classification Criteria Project ${ }^{1}$ database, the 2017 criteria classified 7\% of 214 patients from the DM subgroup as PM. The agreement between physician subtype diagnosis and the 2017 subclassification tree at a probability of $55 \%$ and $90 \%$ was 0.89 and 0.94 , respectively, being the lowest for DM compared with other subtypes. ${ }^{1}$ Cutaneous findings of heliotrope, Gottron's papule or Gottron's sign have been assigned a higher weightage in the 2017 criteria and are also the only cutaneous findings considered for differentiating between DM and PM in the subgroup classification tree. This is justified because for pure DM, the positive predictive value of concurrent heliotrope rash and Gottron's papules of $91 \%$ rises to $100 \%$ with the presence of $\mathrm{V}$-sign and/or shawl sign. ${ }^{3}$ It is however worth noting that the sensitivity for Gottron's papule at $60 \%-80 \%$ and heliotrope rash at $30 \%$ for diagnosis of DM is low. Patel et al retrospectively evaluated the likelihood of the skin variables included

\begin{tabular}{lcl}
\hline $\begin{array}{l}\text { Table } 1 \\
\text { criteria }\end{array}$ & Characteristics of DM and PM subgroup as per ACR/EULAR \\
\hline & DM (n=14) & PM (n=12) \\
\hline Mean age in years \pm SD & $46.3 \pm 12.8$ & $40.3 \pm 10.8$ \\
\hline Median time to diagnosis in months (IQR) & $8(6.2-9.7)$ & $2(1-3)$ \\
\hline Female:male & $11: 3$ & $6: 6$ \\
\hline Organ system involved & 14 & 12 \\
\hline Muscle & 14 & 7 \\
\hline Cutaneous & 13 & 11 \\
\hline Constitutional & 11 & 6 \\
\hline Skeletal & 4 & 10 \\
\hline Gastrointestinal & 8 & 8 \\
\hline Pulmonary & 5 & 3 \\
\hline Severity of myositis at onset & & \\
\hline Mild & 2 & 1 \\
\hline Moderate & 0 & 0 \\
\hline Severe & 12 & 11 \\
\hline Cutaneous manifestations & & \\
\hline Heliotrope rash & 5 & na \\
\hline Gottrons papule & 4 & na \\
\hline Gottrons sign & 11 & na \\
\hline Non-specific rash & 6 & 7 \\
\hline ACR/EULAR, American College of Rheumatology/European League Against \\
Rheumatism; DM, dermatomyositis; na, not applicable; PM, polymyositis.
\end{tabular}

in the EULAR/ACR criteria in classifying patients with amyopathic DM $(\mathrm{ADM})$ and found that $26.3 \%$ of ADM would not meet the suggested $55 \%$ minimum probability cut-off to be classified as IIM on the basis of the EULAR/ACR criteria. Also 6\% of ADM did not have any of the three skin variables. They suggested that subtyping of ADM can be improved by expanding the skin variables included. ${ }^{4}$

In the Euro myositis registry cohort $(\mathrm{n}=3067)$, a DM-specific rash was seen in 3.4\% of patients classified as PM using the Bohan Peter IIM classification criteria. $^{5}$

When patients in our study were subclassified using existing 2017 criteria, there was weak agreement between physician and ACR/EULAR criteria (Cohens kappa coefficient $=0.43$ ). The lower coefficient of agreement between physician diagnosis (considered gold standard) and 2017 criteria in our cohort most likely suggest ethnic/geographic variation in prevalence of classic DM cutaneous features. Addition of MSA positivity and perifascicular atrophy (PFA) on muscle biopsy to the EULAR/ACR criteria in our cohort lead to moderate agreement between physician and ACR/EULAR criteria (Cohens kappa coefficient $=0.77$ ).

While discussing the 2017 EULAR/ACR criteria, ${ }^{1}$ the authors do mention that 'a future update of the EULAR/ACR classification criteria should include the more recently identified MSA'. We suggest that just addition of non-classic cutaneous findings at the node of the subclassification tree would substantially improve the sensitivity of the criteria for subtyping patients of DM across different populations.

\section{Irfan Mohammad @ , Phani Kumar Devarasetti, Liza Rajasekhar}

Clinical Immunology and Rheumatology, Nizam's Institute of Medical Sciences, Hyderabad, Telangana, India

Correspondence to Dr Liza Rajasekhar, Rheumatology, Nizam's Institute of Medical Sciences, Hyderabad 500082, India; lizarajasekhar@gmail.com

Funding The authors have not declared a specific grant for this research from any funding agency in the public, commercial or not-for-profit sectors.

Competing interests None declared.

Patient and public involvement Patients and/or the public were involved in the design, or conduct, or reporting, or dissemination plans of this research. Refer to the Methods section for further details.

\section{Patient consent for publication Not required.}

Provenance and peer review Not commissioned; internally peer reviewed. (c) Author(s) (or their employer(s)) 2021. No commercial re-use. See rights and permissions. Published by BMJ.

\section{Check for updates}

To cite Mohammad I, Devarasetti PK, Rajasekhar L. Ann Rheum Dis Epub ahead of print: [please include Day Month Year]. doi:10.1136/annrheumdis-2020-219426

Received 31 October 2020

Accepted 3 November 2020

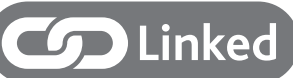

- http://dx.doi.org/10.1136/annrheumdis-2020-219436

Ann Rheum Dis 2021;0:1. doi:10.1136/annrheumdis-2020-219426

\section{ORCID iD}

Irfan Mohammad http://orcid.org/0000-0002-6977-8035

\section{REFERENCES}

1 Lundberg IE, Tjärnlund A, Bottai M, et al. 2017 European League against Rheumatism/ American College of rheumatology classification criteria for adult and juvenile idiopathic inflammatory myopathies and their major subgroups. Ann Rheum Dis 2017;76:1955-64.

2 Bohan A, Peter JB. Polymyositis and dermatomyositis (first of two parts). N Engl J Med 1975;292:344-7.

3 Troyanov Y, Targoff IN, Payette M-P, et al. Redefining dermatomyositis: a description of new diagnostic criteria that differentiate pure dermatomyositis from overlap myositis with dermatomyositis features. Medicine 2014;93:318-32.

4 Patel B, Khan N, Werth VP. Applicability of EULAR/ACR classification criteria for dermatomyositis to amyopathic disease. J Am Acad Dermatol 2018;79:77-83.

5 Lilleker JB, Vencovsky J, Wang G, et al. The EuroMyositis registry: an international collaborative tool to facilitate myositis research. Ann Rheum Dis 2018;77:30-9. 